\title{
Neutrophilic progression in the myeloproliferative neoplasms: molecular insights and potential therapeutic implications
}

\author{
Stephen E Langabeer* \\ Cancer Molecular Diagnostics, St. James's Hospital, Dublin, Ireland
}

Disease evolution of the classical Philadelphia chromosomenegative myeloproliferative neoplasms (MPN) usually manifests as either myelofibrotic transformation of polycythemia vera (PV) and essential thrombocythemia (ET) or to a blast crisis resembling acute myeloid leukemia (AML) that can occur in PV, ET or primary myelofibrosis (PMF) [1,2]. An alternative but less well documented course is that of neutrophilic progression. Throughout the literature there exist sporadic case reports of $\mathrm{PV}$, or more rarely $\mathrm{PMF}$, progressing to or terminating in a marked hyperleukocytosis often resembling chronic neutrophilic leukemia (CNL) and which have exhibited a poor overall survival [310]. Since the discovery of activating CSF3R mutations of exons 14 and 17 in patients with CNL [11], it has become clear that these mutations are now considered a hallmark of CNL with identification rapidly incorporated into classification guidelines $[12,13]$. The most common CNL-associated CSF3R mutation is the T618I that activates the JAKSTAT pathway, providing a rationale for targeted therapy with JAK1/2 inhibitors [11], borne out by some clinical evidence of efficacy [14-16]. Given that a diagnosis of CNL is now nearly defined by the presence of CSF3R mutations, the aforementioned proposed CNL transformation of MPN (and treatment with JAK1/2 inhibitors) can be largely dispelled by proving their absence.

Two recent case studies have illuminated the molecular basis of this rare neutrophilic progression. A patient with longstanding JAK2 V617F-positive PV developed a $B C R-A B L 1$-negative hyperleukocytosis without bone marrow dysplasia, fibrosis, or an increase in myeloblasts, mimicking CNL but with a persistence of morphological features of the underlying PV. Sanger sequencing of CSF3R exons 14-17 did not detect any mutations [17]. A next-generation sequencing targeted for myeloid malignancies was applied to sequential samples from a JAK2 V617Fpositve PMF patient undergoing such a neutrophilic progression. This approach again did not again detect any mutations in CSF3R exons 14 and 17 but demonstrated acquisition of a single NRAS mutation coinciding with the hyperleukocytosis, independent of a stable JAK2 V617F allele burden [18]. The RAS/RAF/MEK pathway interacts with JAK/STAT signalling and is necessary for G-CSF directed proliferation in normal hematopoiesis. Regulation of MEK activity is central to the equilibrium between proliferation and differentiation responses to G-CSF and therefore constitutes a therapeutic target in this case of neutrophilic progression. Clinically available inhibitors of MEK, such as trametinib, have exhibited some effectiveness in NRAS mutated myeloid malignancies [19] and in a rare case of hyperleukocytosis in a patient with NRAS mutated atypical chronic myeloid leukemia [20].

The possibility therefore exists that those historical CNL JAK2 V617F-positive cases might represent patients with polycythaemia vera or primary myelofibrosis presenting in this terminating neutrophilic stage [21-23]. Incidental evidence supporting this speculation comes from the favorable clinical response of sporadic JAK2 V617F-positive CNL patients treated with interferon and hydroxyurea: agents with proven efficacy in the classical MPN [24-26].

Evaluation of the molecular landscape by next-generation sequencing approaches in such uncommon MPN evolution events therefore has the capacity to reveal the underlying molecular landscape and potentially provide targets for specific inhibitors. However, it must also be appreciated that epigenetic and germ line factors also play a role in MPN development and progression. Further understanding of this rare neutrophilic progression of MPN will come from recognition and investigation of additional cases.

\section{Authorship and contributorship}

The author is the sole contributor to the article.

\section{Acknowledgements}

None

\section{Funding}

None

\section{Competing interests}

The author declares no competing interests

\section{References}

1. Mascarenhas J (2016) A concise update on risk factors, therapy, and outcome of leukemic transformation of myeloproliferative neoplasms. Clin Lymphoma Myeloma Leuk 16: S124-S129.

2. Tefferi A, Barbui T (2017) Polycythemia vera and essential thrombocythemia: 2017 update on diagnosis, risk-stratification, and management. Am J Hematol 92: 94-108. [Crossref]

3. Lugassy G, Farhi R (1989) Chronic neutrophilic leukemia associated with polycythemia vera. Am J Hematol 31: 300-301. [Crossref]

Correspondence to: Stephen E Langabeer, Cancer Molecular Diagnostics, Central Pathology Laboratory St. James's Hospital, Dublin 8, Ireland, Tel: +353 1 4103576; Fax: +353 1 4103513; E-mail: slangabeer@stjames.ie

Key words: mutations, myeloproliferative neoplasms, neutrophilic progression, targeted therapy

Received: December 03, 2017; Accepted: December 22, 2017; Published: December 26, 2017 
4. Iurlo A, Foa P, Maiolo AT, Luksch R, Capsoni F, et al. (1990) Polycythemia vera terminating in chronic neutrophilic leukemia: report of a case. Am J Hematol 35: 139140. [Crossref]

5. Stewart K, Carstairs KC, Dubé ID, Keating A (1990) Neutrophilic myelofibrosis presenting as Philadelphia chromosome negative BCR non-rearranged chronic myeloid leukemia. Am J Hematol 34: 59-63. [Crossref]

6. Fujisawa S, Matuzaki M, Harano H, Matomura S, Okubo T, et al. (1992) Polycythemia vera terminating in chronic neutrophilic leukemia: studies on in vitro growth of hematpoietic progenitor cells. Rinsho Ketsueki 33: 1863-1868.

7. Harada Y, Katano T, Nakamura Y, Adachi Y (1993) A case of chronic neutrophilic leukemia associated with polycythemia vera. Rinsho Ketsueki 34: 738-742. [Crossref]

8. Higuchi T, Oba R, Endo M, Harada H, Mori H, et al. (1999) Transition of polycythemia vera to chronic neutrophilic leukemia. Leuk Lymphoma 33: 203-206. [Crossref]

9. Billio A, Venturi R, Morello E, Rosanelli C, Pescosta N, et al. (2001) Chronic neutrophilic leukemia evolving from polycythemia vera with multiple chromosome rearrangements: a case report. Haematologica 86: 1225-1226.

10. Lee SS1, Moon JH, Ha JW, Lee YK, Ahn JS, et al. (2004) A case of transition of polycythemia vera to chronic neutrophilic leukemia. Korean J Intern Med 19: 285-288. [Crossref]

11. Maxson JE, Gotlib J, Pollyea DA, Fleischman AG, Agarwal A, et al. (2013) Oncogenic CSF3R mutations in chronic neutrophilic leukemia and atypical CML. $N$ Engl J Med 368: 1781-1790. [Crossref]

12. Pardanani A, Lasho TL, Laborde RR, Elliot M, Hanson CA, et al. (2013) CSF3R T618I is a highly prevalent and specific mutation in chronic neutrophilic leukemia. Leukemia 27: $1870-1873$.

13. Maxson JE, Tyner JW (2017) Genomics of chronic neutrophilic leukemia. Blood 129: 715-722. [Crossref]

14. Dao KH, Solti MB, Maxson JE, Winton EF, Press RD, et al. (2014) Significant clinical response to JAK $1 / 2$ inhibition in a patient with CSF3R T618I-positive atypical chronic myeloid leukemia. Leuk Res Rep 3: 67-69.

15. Stahl M, Xu ML, Steensma DP, Rampal R, Much M, et al. (2016) Clinical response to ruxolitinib in CSF3R T618-mutated chronic neutrophilic leukemia. Ann Hematol 95: 1197-1200. [Crossref]
16. Gunawan AS, McLornan DP, Wilkins B, Waghorn K, Hoade Y, et al. (2017) Ruxolitinib, a potent JAK1/JAK2 inhibitor, induces temporary reductions in the allelic burden of concurrent CSF3R mutations in chronic neutrophilic leukemia. Haematologica 102: e238-e240.

17. Castelli R, Cugno M, Gianelli U, Pancrazzi A, Vannucchi AM (2015) Neutrophilic progression in a case of polycythemia vera mimicking chronic neutrophilic leukemia: clinical and molecular characterization. Pathol Res Pract 211: 341-343.

18. Langabeer SE, Haslam K, Groarke E, Conneally E (2017) An acquired NRAS mutation contributes to neutrophilic progression in a patient with primary myelofibrosis. $\mathrm{Br} \mathrm{J}$ Haematol.

19. Borthakur G, Popplewell L, Boyiadzis M, Foran J, Platzbecker U, et al. (2016) Activity of the oral mitogen-activated protein kinase kinase inhibitor trametinib in RAS-mutant relapsed or refractory myeloid malignancies. Cancer 122: 1871-1879.

20. Khanna V, Pierce ST, Dao KH, Tognon CE, Hunt DE, et al. (2015) Durable disease control with MEK inhibition in a patient with NRAS-mutated atypical chronic myeloid leukemia. Cureus 7: e414.

21. McLornan DP, Percy MJ, Jones AV, Cross NC, McMullin MF (2005) Chronic neutrophilic leukemia with an associated V617F JAK2 tyrosine kinase mutation. Haematologica 90: 1696-1697.

22. Lea NC, Lim Z, Westwood NB, Arno MJ, Gäken J, et al. (2006) Presence of JAK2 V617F tyrosine kinase mutation as a myeloid lineage-specific mutation in chronic neutrophilic leukemia. Leukemia 20: 1324-1326.

23. Imashuku S, Kudo N, Kubo K, Saigo K, Okuno N, et al. (2012) Rituximab for managing acquired haemophilia $\mathrm{A}$ in a case of chronic neutrophilic leukemia with the JAK2 kinase V617F mutation. J Blood Med 3: 157-161.

24. Sugino K, Gocho K, Ota H, Kobayashi M, Sano G, et al. (2009) Miliary tuberculosis associated with chronic neutrophilic leukemia. Intern Med 48: 1283-1287.

25. Zhang X, Pan J, Guo J (2013) Presence of the JAK2 V617F mutation in a patien with chronic neutrophilic leukemia and effective response to interferon $\hat{\mathrm{I}} \pm-2 \mathrm{~b}$. Acta Haematol 130: 44-46. [Crossref]

26. Gajendra S, Gupta R, Chandgothia M, Kumar L, Gupta R1, et al. (2014) Chronic Neutrophilic Leukemia with V617F JAK2 Mutation. Indian J Hematol Blood Transfus 30: 139-142. [Crossref]

Copyright: $\bigcirc 2017$ Langabeer SE. This is an open-access article distributed under the terms of the Creative Commons Attribution License, which permits unrestricted use, distribution, and reproduction in any medium, provided the original author and source are credited. 